\title{
MicroRNA-124 Suppresses Breast Cancer Cell Growth and Motility by Targeting CD151
}

\author{
Zhi-Bo Han ${ }^{\mathrm{a}, \mathrm{c}}$ Zhouxin Yang ${ }^{\mathrm{a}}$ Ying Chi ${ }^{\mathrm{a}}$ Lei Zhang ${ }^{\mathrm{a}}$ Youwei Wang ${ }^{\mathrm{a}}$ Yueru Jia \\ Jinhan Wang ${ }^{b}$ Hui Zhao ${ }^{b, d}$ Zhong Chao Han ${ }^{a, c}$
}

\begin{abstract}
aState Key Laboratory of Experimental Hematology, Institute of Hematology and Hospital of Blood Diseases, Chinese Academy of Medical Sciences and Peking Union Medical College, Tianjin; ${ }^{\text {TTianjin Key }}$ Laboratory of Food and Biotechnology, School of Biotechnology and Food Science, Tianjin University of Commerce, Tianjin; 'TEDA Life Science and Technology Research Center, Institute of Hematology and Blood Diseases Hospital, Chinese Academy of Medical Sciences and Peking Union Medical College, Tianjin; 'Department of Hematology, the Affiliated Hospital of Hebei Union University, Tangshan, Hebei
\end{abstract}

\section{Key Words}

miR-124 • CD151 • Breast cancer • Proliferation • Metastasis

\begin{abstract}
Background: CD151 is highly expressed in breast cancer cells and has been shown to accelerate breast cancer by enhancing cell growth and motility, but its regulation is poorly understood. To explore post-translation regulation of CD151, for example microRNAs, will be of great importance to claim the mechanism. Methods: A luciferase reporter assay was used to determine whether CD151 was a target of miR-124. The levels of CD151 mRNA were detected by real-time PCR, and CD151 protein expression was measured by western blot and flow cytometry. The effects of miR-124 expression on growth, apoptosis, cell cycle and motility of breast cancer cells were determined. Results: We discovered that miR-124 directly targets the 3' untranslated region (3'-UTR) of CD151 mRNAs and suppresses its mRNA expression and protein translation. Both siRNA of CD151 and miR-124 mimics could significantly inhibit proliferation of breast cancer cell lines via cell cycle arrest but does not induce apoptosis. Meanwhile, miR-124 mimics significantly inhibited the motility of breast cancer cells. Conclusion: miR-124 plays a critical role in inhibiting the invasive and metastatic potential of breast cancer cells, probably by directly targeting the CD151 genes. Our findings highlight an important role of miR-124 in the regulation of invasion and metastasis by breast cancer cells and suggest a potential application for miR-124 in breast cancer treatment.
\end{abstract}




\section{Cellular Physiology and Biochemistry}

Cell Physiol Biochem 2013;31:823-832

DOI: $10.1159 / 000350100$

Published onlıne: June 04, 2013

(C) 2013 S. Karger AG, Basel

www.karger.com/cpb

Han/Yang/Chi/Zhang/Wang/Ji/Wang/Zhao/Han: CD151 is a Target of MicroRNA-124

\section{Introduction}

Breast cancer is a type of malignant neoplasm originating from breast tissue. Worldwide, breast cancer is the most common cause of death in women. Gender (females), age, absence of childbearing or breastfeeding, higher hormone levels and ethnic type are recognized as the primary risk factors for breast cancer [1].

Of note, invasion and metastasis indicate an unfavourable prognosis and have always represented a challenge for treating breast cancer. several integrins $(\alpha 6 \beta 4, \alpha 6 \beta 1$ and $\alpha 3 \beta 1)$ are correlated with breast cancer metastasis [2], and increasing evidence suggests that CD151 might be a novel marker for poor prognosis in breast cancer [3, 4]. Originally, CD151 is a member of the tetraspanin family, characterized by the presence of four hydrophobic domains, and mediates signal transduction events involved in cell development, activation, growth and motility [5, 6]. CD151-null mice are viable, healthy, and fertile and show normal mendelian inheritance with a minor abnormality in hemostasis [7]. So far, CD151 has been demonstrated to accelerate the progression of breast cancer by regulating integrin function and facilitating the signalling of transforming growth factor $\beta$ (TGF- $\beta$ ) and hepatic growth factor (HGF) to promote breast cancer metastasis [3, 8, 9].

MicroRNAs (miRNAs) are a class of small, non-coding RNA molecules that negatively regulate the expression of protein-coding genes, and have been implicated in various crucial biological processes. It is well documented that most miRNAs robustly suppress breast cancer metastasis and their expression levels can predict metastasis. miRNA-124 has been identified as the most abundantly expressed miRNA by neuronal cells [10-13]. miR-124 usually expressed in a lower level, which is linked with haematological malignancies and solid tumours including breast cancer and oral tumour [14-17].

Of interest, CD151 highly expressed in breast cancer cell and engaged invasion and metastasis, meanwhile the tumour suppressant miRNA-124 was frequently downregulated. We are interested in seeking the connection between CD151 and miRNA-124, which could provide a deep understanding of the carsinogenesis in breast cancer. In this study, we show that miR-124 negatively regulates the transcription of the CD151 gene by interfering with its 3'UTR, and the degradation of CD151 contributes to the suppression of proliferation and mobility in breast cancer lines.

\section{Materials and Methods}

\section{Bioinformatics}

In silico prediction of miRNA binding sites within the CD151 3'-UTR was performed using TargetScan Human 5.1 (www.targetscan.org). On this basis, we assumed that the CD151 gene might be a direct target regulated by miR-124.

\section{Cell culture and miRNA/siRNA transfection}

Human breast cancer cell lines MCF-7 and MDA-MB-231 were obtained from the Cell Culture Center, Peking Union Medical College (Beijing, China), and routinely cultured in Dulbecco's modified Eagle's medium (DMEM) (Invitrogen) with L-glutamine and 10\% (v/v) foetal bovine serum (FBS; ExCell Bio). Cells were transfected at approximately $60 \%-70 \%$ confluence using Lipofectamine ${ }^{\mathrm{TM}}$ RNAiMAX Reagent (Invitrogen) with miRNA-124 mimics, siRNA targeted to CD151 (Invitrogen) or negative control siRNA (final concentration, 25nM) in Opti-MEM medium (Invitrogen). Cells were incubated for $24 \mathrm{~h}$ prior to harvesting.

Plasmid constructs, transient transfection and luciferase assay

CD151 3'-UTR was amplified from human cDNA using CD151 forward (5' TCT AGA ACC CAA CTA CTG AGC TGA GA) and reverse (5' TCT AGA GTA CAG CAG TGA ACA AAA CCA) primers containing Xba I restriction sites. Putative miR-124 binding sites were abolished using PCR. The following primers were utilized to replace putative seed sequences with complementary bases: CD151 mutate 124 forward (5' CTT CTT CCG AGT TTT GCT GCG CAC CAA TGC) and reverse (CAG CAA AAC TCG GAA GAA GCT GCC TCT GAG GT). The PCR 


\section{Cellular Physiology and Biochemistry}

Cell Physiol Biochem 2013;31:823-832

DOI: $10.1159 / 000350100$

Published onIIne: June 04, 2013

(c) 2013 S. Karger AG, Basel

www.karger.com/cpb

Han/Yang/Chi/Zhang/Wang/Ji/Wang/Zhao/Han: CD151 is a Target of MicroRNA-124

fragment was cloned into pGL3 control vectors (Promega). Nominated pGL3-CD151, pGL3-mCD151, MCF-7 and MDA-MB-231 cells were co-transfected using Lipofectamine ${ }^{\mathrm{TM}} 2000$ reagent (Invitrogen) with $500 \mathrm{ng}$ of the 3'-UTR-luciferase reporter vector, $100 \mathrm{ng}$ of pRL-TK Renilla luciferase control vector (Promega) and miRNA-124 mimics or negative control siRNA (final concentration, $50 \mathrm{nM}$ ). After $24 \mathrm{~h}$ incubation, Luciferase activity was determined using the Dual Luciferase Reporter Assay System (Promega), according to the manufacturer's instructions.

RNA isolation, RT-PCR and quantitative real-time PCR

Total RNA was isolated from MCF-7 and MDA-MB-231 cells using the E.Z.N.A® Total RNA Kit (Omega Bio-tek). cDNA preparation was performed according to standard procedures using SuperScript ${ }^{\circ}$ VILO $^{\text {TM }}$ Master Mix (Invitrogen). cDNA was amplified by RT-PCR (ABI 2700) using PrimeSTAR DNA Polymerase (Takara) and quantitative real-time PCR (ABI 7300) using SYBR Green PCR master mix reagent (ABI) and primers for CD151 and GAPDH. All values were normalized to GAPDH expression levels. Human CD151 forward: 5' ACA GCC TAC ATC CTG GTG GT, reverse: 5' TTC TCC TTG AGC TCC GTG TT; human GAPDH forward: 5' TCC ACT GGC GTC TTC ACC A, reverse: 5' CTG TGG TCA TGA GTC CTT CC.

Flow cytometry analysis

After trypsinization, cells were counted using a haemocytometer, resuspended in serum-free DMEM (2 $\times 10^{6} / \mathrm{ml}$ ) and were then allowed to react on ice for $30 \mathrm{~min}$ with fluorescent-labelled mouse antibodies (BD Biosciences) raised against IgG1 or CD151 and washed with cold PBS. Data acquisition was performed with a FACSCalibur ${ }^{\mathrm{TM}}$ flow cytometer (BD Biosciences) and analysed with CellQuest ${ }^{\mathrm{TM}}$ software (BD Biosciences).

\section{Protein extraction and Western blotting}

Cells were washed twice with Dulbecco's phosphate buffered saline (PBS) and proteins were lysed with SDS lysis buffer (Beyotime) supplemented with proteinase inhibitor cocktail (Sigma) and fractioned by $15 \%$ SDS-polyacrylamide gel electrophoresis. Protein samples were then immunoblot assayed using anti-CD151 (sc-80715) and anti-actin (sc-8432) (Santa Cruz Biotechnology). We used the Protein Detector LumiGLO Reserve Western Blotting Kit (KPL Gaithersburg) to test immunoblotted bands, according to the manufacturer's instructions.

\section{MTT cell proliferation assay}

Cell growth was measured by MTT assay. Cells were seeded in 96-well culture dishes (Costar) at an initial density of $5 \times 10^{3}$ cells/well. Either the next morning $(0 \mathrm{~h})$ or $72 \mathrm{~h}$ later, the cells were incubated for $1 \mathrm{~h}$ with 3-(4,5-dimethylthiazol-2-yl)-2,5-diphenyltetrazolium bromide (MTT) diluted in culture medium. Eventually, $100 \mu \mathrm{l}$ of dimethyl sulfoxide (DMSO) was added to each well to dissolve the coloured product of the mitochondrial-based reaction, and the optical density was measured at $570 \mathrm{~nm}$ in a microtitre plate reader.

\section{Apoptosis analysis}

Treated cells were collected by trypsinization and centrifugation and washed twice with cold PBS and then resuspended in $1 \times$ Binding buffer at a concentration of $1 \times 10^{6}$ cells $/ \mathrm{ml}$. Then $100 \mu \mathrm{l}$ of the solution $\left(1 \times 10^{5}\right.$ cells) was transferred to a $5 \mathrm{ml}$ culture tube and $5 \mu \mathrm{l}$ of Annexin V-FITC(Sungene Biotech) and $5 \mu \mathrm{l}$ 7-AAD were added. The cells were then gently vortex and incubated for 20 minutes at room temperature in the dark. After the incubation, $400 \mu \mathrm{l}$ of binding buffer was added to each tube and was analyzed with BD FACSCalibur ${ }^{\mathrm{TM}}$ flow cytometry (BD Biosciences, San Jose, CA) within 1 hour. Data was analysed using CellQuest software.

\section{Cell cycle analysis}

Treated cells were collected by trypsinization and fixed with 70\% ethanol in PBS. Cells were suspended in $250 \mu \mathrm{l}$ of PBS after washing and treated with $100 \mu \mathrm{l}$ of RNase $\mathrm{A}(1 \mathrm{mg} / \mathrm{ml})$ for $30 \mathrm{~min}$ at $37^{\circ} \mathrm{C}$, following with propidium iodide(PI) staining at $40 \mu \mathrm{g} / \mathrm{ml}$ in the dark at room temperature for $30 \mathrm{~min}$. The samples were analyzed with BD FACSCalibur ${ }^{\mathrm{TM}}$ flow cytometry (BD Biosciences, San Jose, CA) within 1 hour. Data was analysed using ModFIT software. 
Fig. 1. miR-124 targets CD151 3'UTR. (A) Bioinformatics analyses of the 3'-UTR of human CD151 mRNA binding to miR-124 at position 140-160. (B) The 3'-UTR of CD151 gene plasmid constructs used for luciferase assays. pGL3CD151 contains wild-type miR124 binding sites, while pGL3mCD151 contains mutated miR-124 binding sites. (C) Relative luciferase assays of pGL3-CD151 and pGL3mCD151 (non-paired $t$-test, $n=3$, $\left.{ }^{*} p<0.05\right)$.

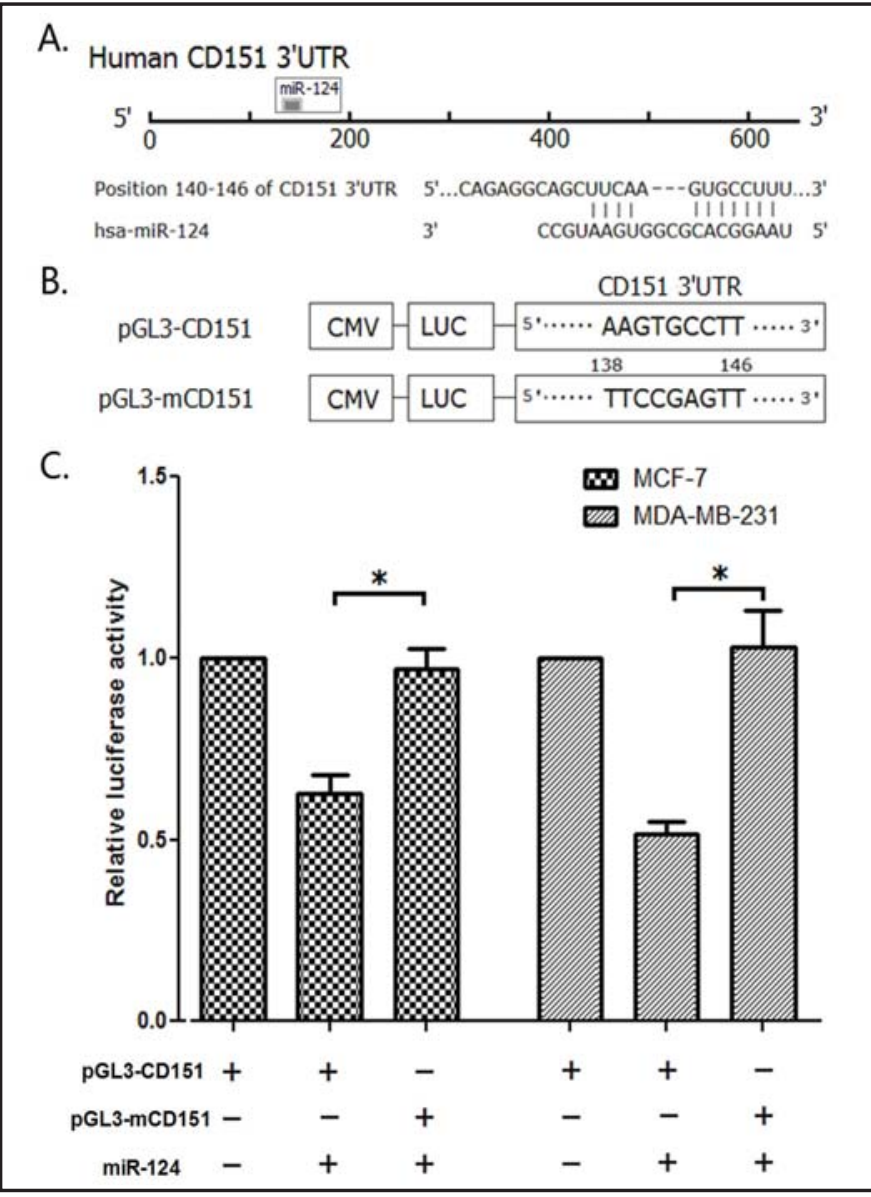

Cell motility assay

Cell motility was measured by wound healing assay. Cells were plated on 6-well culture dishes (Costar), grown to a confluent monolayer, and then wounded by scraping the monolayer with a $200 \mu$ pipette tip. Cells were further cultured for $24 \mathrm{~h}$, and the wound healing region was observed microscopically at various time points. Crystal violet was then added for $5 \mathrm{~min}$, and cells were rinsed in running tap water.

\section{Statistics}

The results are shown as mean \pm SD. Statistical analysis was performed using non-paired $t$-testing, and a $p$ value $<0.05$ was considered statistically significant.

\section{Results}

miR-124 targets CD151

miRNAs are categorized as post-transcriptional controllers because of their ability to bind to complementary sequences, resulting in the repression or silencing of target genes. miRNAs in a variety of human cancers usually silence and lose of their suppressing effects on the metastatic phenotype of tumours. To date, miRNAs represent a group of highly attractive putative biomarkers in human breast cancer.

Based on bioinformatics prediction, screening of three prime untranslated regions (3'-UTR) of CD151 gene, a tumour metastasis accelerator, revealed a potential miR-124binding site near to position 140-146 (Fig. 1A). So we aimed to examine the impact of miR124 on CD151 and determine whether miR-124 can act as a tumour suppressor. We therefore transfected breast cancer lines MCF-7 and MDA-MB-231 with wild-type or mutated promoters of CD151 gene plasmid constructs (Fig. 1B). Next, we added miR-124 analogues to the cells. 


\section{Cellular Physiology \\ Cell Physiol Biochem 2013;31:823-832 and Biochemistry

Fig. 2. miR-124 suppressed CD151 mRNA transcription. (A) Agarose gel electrophoresis of RT-PCR of MCF-7 and MDA-MB-231 under different treatments. (B) Real-time PCR of MCF-7 and MDA-MB-231 cells under different treatments (non-paired $t$-test, $n=3,{ }^{*} p<0.05$ ).

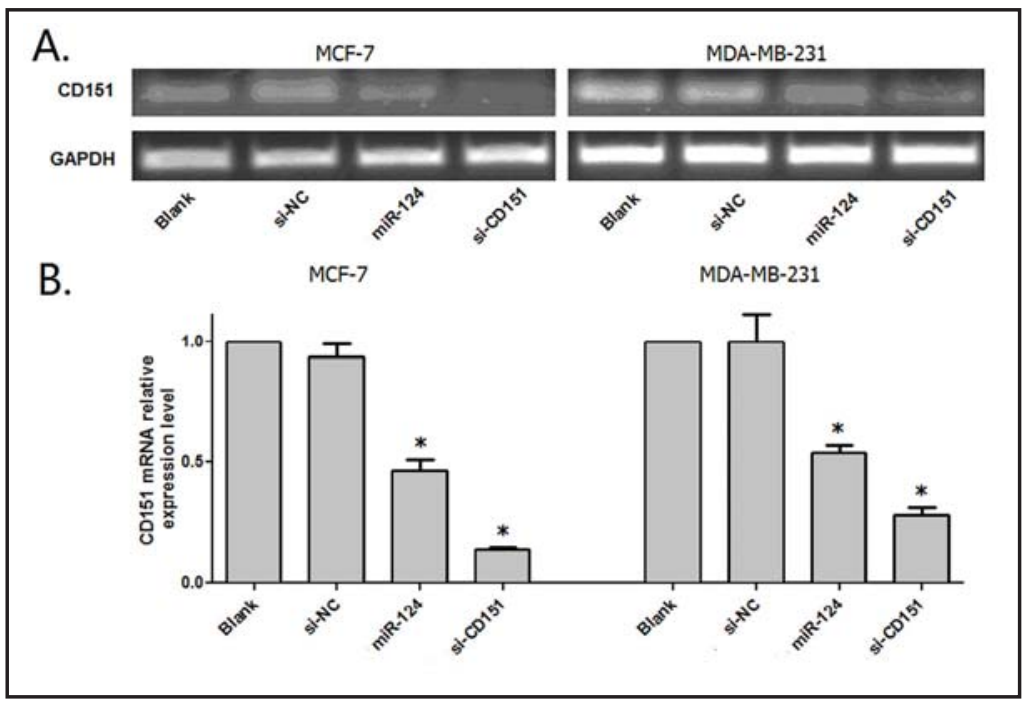

Fig. 3. miR-124 suppressed CD151 protein expression. Data are expressed as mean +SD. (A) Representative western blotting analysis of MCF-7 and MDA-MB-231 cells under different treatments. (B,C) Flow cytometry analysis of mean flourscence indensity of CD151 expressed in MCF-7 and MDA-MB-231 cells under different treatments. si$\mathrm{NC}(5 \mathrm{nM})$, si-CD151(5nM), or miR-124(1 and 5nM) were added to the culture medium, respectively. CD151 expression was reduced to nearly 30 percent when treated with miR-124.

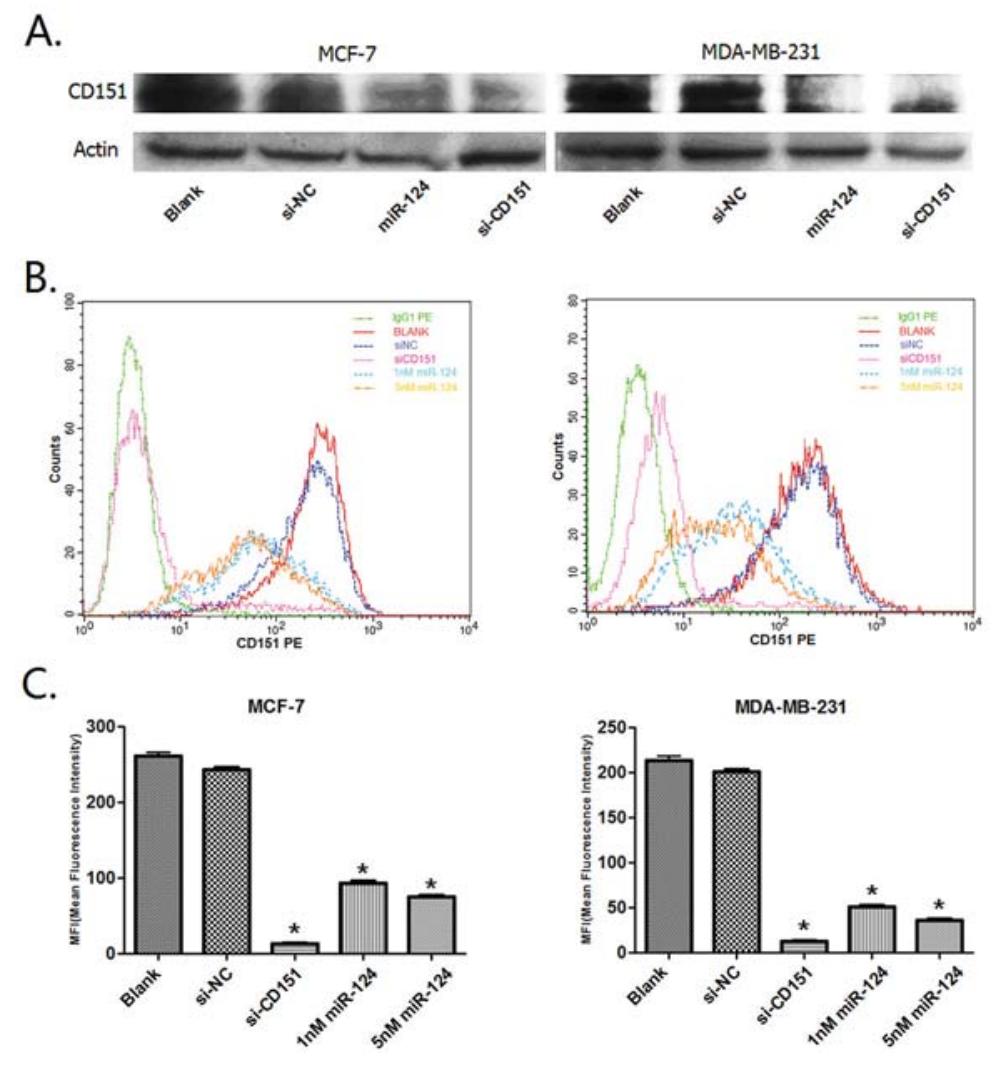

As expected, the cells transfected with wild-type CD151 3'-UTR constructs exhibited a lower luciferase activity compared with mutant constructs (Fig .1C). These results indicated that miR-124 binded to CD151 3'-UTR.

miR-124 causes degradation of the CD151 transcript and abrogation of CD151 protein miRNAs can alter the stability of mRNA expression to regulate protein translation. To elucidate whether miR-124 has regulating action, CD151 mRNA was measured following 

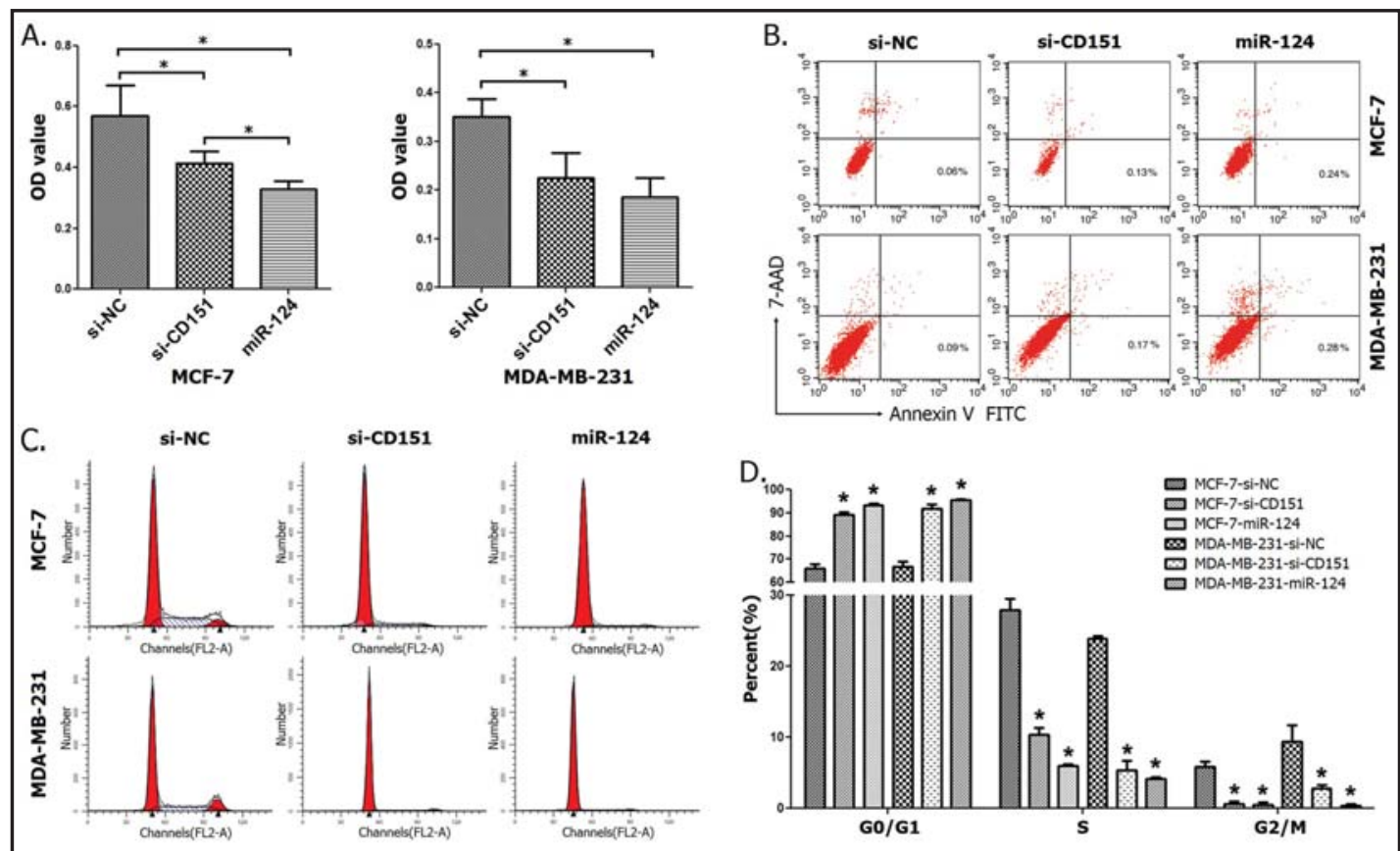

Fig. 4. miR-124 inhibits proliferation of MCF-7 and MDA-MB-231 cells via cell cycle arrest. (A) MCF-7 and MDA-MB-231 cells were treated with si-NC(5nM), si-CD151(5nM), or miR-124(5nM), respectively. MTT assay were used to test the proliferation of cells (non-paired t-test, $n=3, * p<0.05$ ). (B) si-CD151 and miR124 didn't promote apoptosis of MCF-7 and MDA-MB-231 cells. Flow cytometry were used to detect apoptosis of these cells. (C) si-CD151 and miR-124 induced cell cycle of MCF-7 and MDA-MB-231 cells arrest at G0/G1 phase. (D) The cell cycle results of three separate experiments (non-paired t-test, ${ }^{*} \mathrm{p}<0.05$ ).

the addition of miR-124 or si-CD151 (a positive control). The results showed that the CD151 mRNA expression decreased in both MCF7 and MDA-MB-231 in the presence of miR-124. (Fig 2A, B). And CD151 protein level in both MCF-7 and MDA-231 was found to be downregulated in the presence of si-CD151 or miR-124 (Fig.3 A,B,C). We have tested different concentrations of miR-124, and 1-5 nM of miR-124 was proved sufficiently to downregulate CD151 translation.

miR-124 inhibits cell proliferation of MCF-7 and MDA-MB-231

Proliferation ability is one of important characters of cancer cells, and CD151 is considered to regulate the proliferation of cancer cells. In our study, we noticed that either siCD151 or miR-124 downregulated the proliferation of MCF-7 and MDA-MB-231 (Fig. 4A). In MCF-7, the anti-proliferation ability of miR-124 was significantly more effective than that of si-CD151. But in MDA-MB-231, miR-124 had the similar anti-proliferation ability compared with si-CD151.

To explore if miR-124 induce apoptosis through suppressing CD151 activity, we test the apoptosis of the MCF-7 and MDA-MB-231 cells. But very low proportion of apoptosis cells (lower than 1\%) was found in both MCF-7 and MDA-MB-231 cells under these conditions (Fig. 4B). We considered that miR-124 may affect cell viability. Then we analyzed cell cycle of these cells. We found that both si-CD151 and miR-124 induced cell cycle of MCF-7 and MDAMB-231 cells arrest at G0/G1 phase. (Fig. 4C, D). The proportion of cells in G0/G1 phase were effectively up regulated $(\mathrm{p}<0.05)$ and cells in $\mathrm{G} 2 / \mathrm{M}$ phase were effectively down regulated after treating with si-CD151 or miR-124 $(\mathrm{p}<0.05)$. These results proved that miR-124 inhibit proliferation of breast cancer cell lines MCF-7 and MDA-MB-231 via cell cycle arrest. 


\section{Cellular Physiology and Biochemistry}

Cell Physiol Biochem 2013;31:823-832

DOI: $10.1159 / 000350100$

Published online: June 04, 2013

S. Karger AG, Basel

Han/Yang/Chi/Zhang/Wang/Ji/Wang/Zhao/Han: CD151 is a Target of MicroRNA-124

Fig. 5. miR-124 inhibits MCF-7 and MDA-MB-231 cells motility (A) Image of cell wound healing region after $24 \mathrm{~h}$ incubation. (B) Statistical analysis for wound healing experiments (non-paired $t$-test, $n=3$, $* p<0.05$ ).

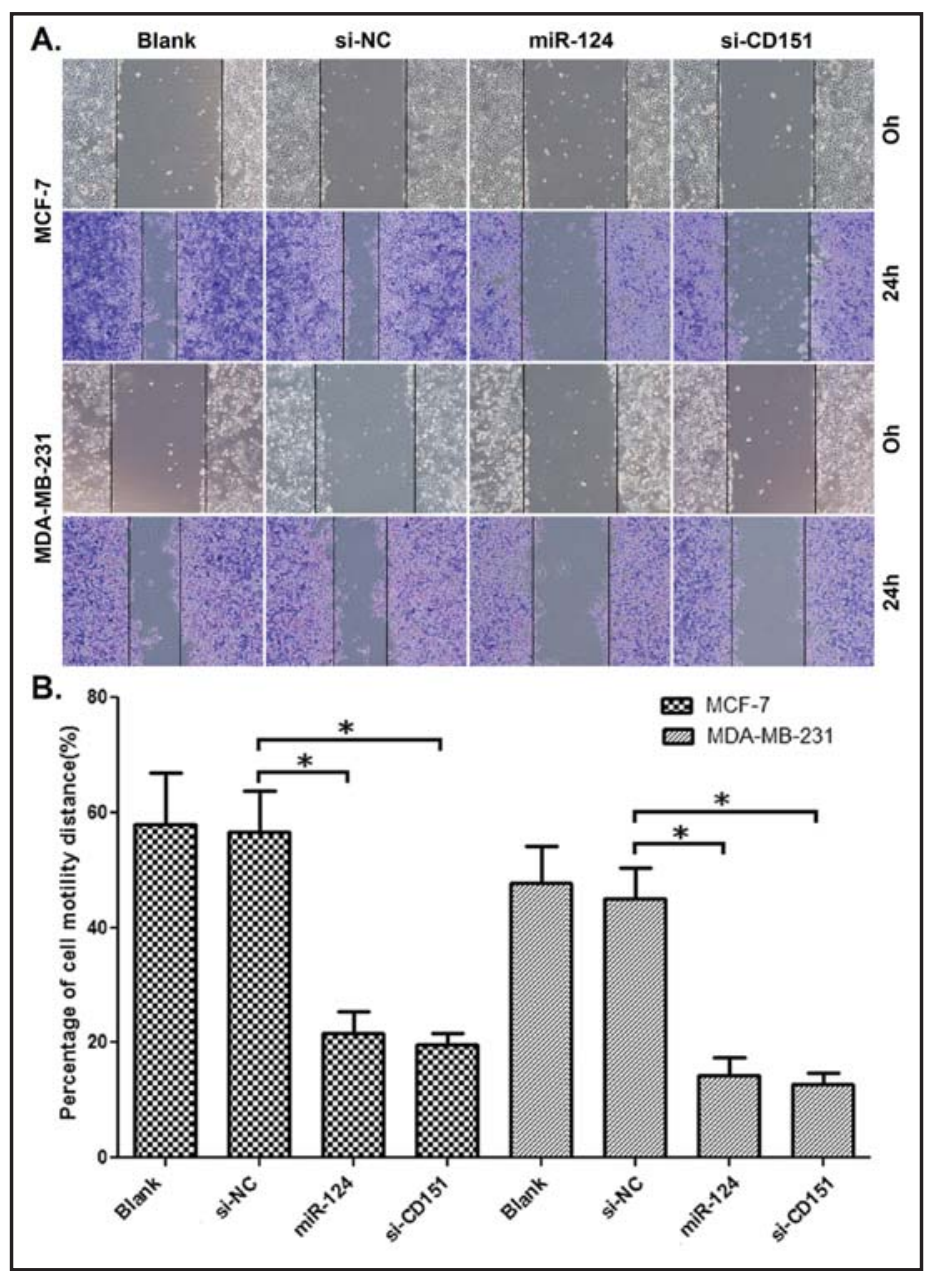

miR-124 inhibits MCF-7 and MDA-MB-231 cell motility

Metastasis is a key characteristic of breast cancer and is directly associated with the motility of cancer cells. To examine the effect of miR-124 on breast cancer cell motility, miR124 or si-CD151 were added into the culture medium, the motility of cancer cell lines MCF-7 and MDA-MB-231 was effectively abolished (Fig. 5A, B). These findings indicated that miR124 and its target CD151 are critical to the motility potential of breast cancer cell lines.

\section{Discussion}

In our study, we discovered an important downstream target of miR-124, CD151, a surface protein widely expressed in tumour cells, which is critical in the mediation of tumour growth and metastasis. The addition of either miR-124 or si-CD151 negated breast cancer cell line proliferation and motility. The effect of miR-124 on breast cancer cell lines is, to some extent, largely dependent on the down regulation of CD151, and this study sheds new light on the regulation of breast cancer progress by miRNAs.

Since around 1000 identified miRNAs are suggested to regulate approximately $30 \%$ of human genes, it seems very likely that these regulations are involved in most biological processes [18]. Some tumour-suppressant miRNAs are down regulated in certain tumour types, the downstream targeting tumour suppressor genes may be up regulated and contribute to cancer cell survival [19-21].

In mouse, miR-124 is highly expressed in central nervous system, including the cerebral cortex, cerebellum and spinal cord, compared with other organs [13] and is believed to be 


\section{Cellular Physiology and Biochemistry}

Cell Physiol Biochem 2013;31:823-832

involved in embryonic development and neuronal differentiation [12, 14, 22]. However, the expression of miR-124 is very low in many types of cancer cell $[16,23,24]$. miR-124 is usually considered as a tumour-suppressant miRNAs that induces down regulation in many different cancer types, including both solid tumors and hematologic malignancy [23, 25]. However, the mechanism by which miR-124 regulates tumour growth and metastasis is not fully understood. It was reported that member 1 of solute carrier family 16 is a target for miR124 , and may be the mechanism by which miR-124 suppresses malignant medulloblastoma [24]. Xia and co-workers also reported that miR-124 inhibited the proliferation and tumorigenicity of gastric cancer cells via the regulation of SPHK1[17]. Our current study provided new evidence that miR-124 suppressed breast cancer and, more importantly, CD151 was a novel target for miR-124-based tumour suppression.

As a tetraspanin family member, CD151 modulates the ligand binding activity of integrin $\alpha 3 \beta 1$. CD151 promote metastasis of cancer cells [26, 27]. Also, CD151 is reported to play a role in Met-dependent signalling and the TGF- $\beta$ signalling $[9,28]$, while c-met play a role in proliferation and migration of human lung and salivary gland cancer cells $[29,30]$. CD151 is highly expressed in loads of cancer cells and promotes tumour progression $[4,31$, 32]. In breast cancer, CD151 overexpression was found to be significantly associated with larger tumour size, higher nodal stage and advanced stage[4]. Transfection of CD151 cDNA into cancer cell lines RPMI4788, A172 and HT1080 induced enhancement of cell motility and invasion and metastasis of cancer cells [33]. Depletion of CD151 attenuates pulmonary metastasis by breast cancer cells and the immediate trafficking of breast cancer cells to the lungs in vivo. In breast cancer cell lines, TGF $\beta 1$-induced scattering and proliferation of CD151deficient cells in three-dimensional matrigel was dramatically reduced when compared with the control, CD151-positive cells [9].

Here, we confirmed that miR-124 inhibited breast cancer cell growth relating to targeting CD151, and the miR-124-CD151 axis contributed to the proliferation and migration of breast cancer cells. However, miR-124 may be present in neuroblastoma but not in all types of tumours [34]. This reflects the heterogeneity and complexity of tumors; further research should be carried out to discover the mechanisms by which miR-124 differentially affects the proliferation of breast cancer and neuroblastoma. Of course, a microRNA usually has more than one target. So we utilized flow cytometry to test CD29, a known target integrin beta 1 (fibronectin receptor, beta polypeptide, antigen CD29 includes MDF2, MSK12) reported by Hunt et al previously [35]. Interestingly, we found miR-124 had more profound impact on CD151 expression compared with CD29 (Data not shown). Additionally, signalling system of the CD151 cascade may involve too many pathways that are difficult to dissect out or redundant. In breast cancer, several previous studies had verified that CD151 signalling definitely acts as a tumor matastasis accelerator. Our research showed the direct correlation of miR-124 and CD151, which might strengthen evidence that miR-124 serves as a breast cancer matastasis suppressor. Other miR-124 targeting genes might also be important for inhibition of cancer cell lines, as these genes may possess synergistic effect.

In summary, we identified a new role of miR-124 regulation in breast cancer cells: miR-124 suppresses the growth and motility of breast cancer cells, and this ability is highly associated with its target, CD151. As a corollary, the miR-124-CD151 axis may represent a target for breast cancer treatment.

\section{Conflict of Interest}

The authors declare no competing financial interests. 


\section{Cellular Physiology \\ and Biochemistry}

Cell Physiol Biochem 2013;31:823-832

\begin{tabular}{l|l}
\hline DOI: $10.1159 / 000350100$ & (c) 2013 S. Karger AG, Basel
\end{tabular}

www.karger.com/cpb

Han/Yang/Chi/Zhang/Wang/Ji/Wang/Zhao/Han: CD151 is a Target of MicroRNA-124

\section{Acknowledgements}

We thank Dr Lu Liang (National Engineering Research Center of Cell Products, China) for advises on writing.This study was supported by National Basic Research Program of China 2011CB964800 (2011CB964802). The 863 Project of Ministry of Science and Technology of China (2012AA02A211), National Natural Science Foundation of China (81270595, 81172837).

\section{References}

1 Kelsey JL, Gammon MD, John EM: Reproductive factors and breast cancer. Epidemiol Rev 1993;15:36-47.

2 Howlett AR, Bailey N, Damsky C, Petersen OW, Bissell MJ: Cellular growth and survival are mediated by beta 1 integrins in normal human breast epithelium but not in breast carcinoma. J Cell Sci 1995;108:19451957.

-3 Yang XH, Richardson AL, Torres-Arzayus MI, Zhou P, Sharma C, Kazarov AR, Andzelm MM, Strominger JL, Brown M, Hemler ME: Cd151 accelerates breast cancer by regulating alpha 6 integrin function, signaling, and molecular organization. Cancer Res 2008;68:3204-3213.

- 4 Kwon MJ, Park S, Choi JY, Oh E, Kim YJ, Park YH, Cho EY, Nam SJ, Im YH, Shin YK, Choi YL: Clinical significance of cd151 overexpression in subtypes of invasive breast cancer. Br J Cancer 2012;106:923-930.

5 Hong IK, Jeoung DI, Ha KS, Kim YM, Lee H: Tetraspanin cd151 stimulates adhesion-dependent activation of ras, rac, and cdc42 by facilitating molecular association between beta1 integrins and small gtpases. J Biol Chem 2012;287:32027-32039.

6 Yunta M, Lazo PA: Tetraspanin proteins as organisers of membrane microdomains and signalling complexes. Cell Signal 2003;15:559-564.

7 Wright MD, Geary SM, Fitter S, Moseley GW, Lau LM, Sheng KC, Apostolopoulos V, Stanley EG, Jackson DE, Ashman LK: Characterization of mice lacking the tetraspanin superfamily member cd151. Mol Cell Biol 2004;24:5978-5988.

8 Klosek SK, Nakashiro K, Hara S, Goda H, Hasegawa H, Hamakawa H: Cd151 regulates hgf-stimulated morphogenesis of human breast cancer cells. Biochem Biophys Res Commun 2009;379:1097-1100.

-9 Sadej R, Romanska H, Kavanagh D, Baldwin G, Takahashi T, Kalia N, Berditchevski F: Tetraspanin cd151 regulates transforming growth factor beta signaling: Implication in tumor metastasis. Cancer Res 2010;70:6059-6070.

10 Cheng LC, Pastrana E, Tavazoie M, Doetsch F: Mir-124 regulates adult neurogenesis in the subventricular zone stem cell niche. Nat Neurosci 2009;12:399-408.

-11 Yu JY, Chung KH, Deo M, Thompson RC, Turner DL: Microrna mir-124 regulates neurite outgrowth during neuronal differentiation. Exp Cell Res 2008;314:2618-2633.

12 Makeyev EV, Zhang J, Carrasco MA, Maniatis T: The microrna mir-124 promotes neuronal differentiation by triggering brain-specific alternative pre-mrna splicing. Mol Cell 2007;27:435-448.

-13 Mishima T, Mizuguchi Y, Kawahigashi Y, Takizawa T: Rt-pcr-based analysis of microrna (mir-1 and -124) expression in mouse cns. Brain Res 2007;1131:37-43.

- 14 Silber J, Lim DA, Petritsch C, Persson AI, Maunakea AK, Yu M, Vandenberg SR, Ginzinger DG, James CD, Costello JF, Bergers G, Weiss WA, Alvarez-Buylla A, Hodgson JG: Mir-124 and mir-137 inhibit proliferation of glioblastoma multiforme cells and induce differentiation of brain tumor stem cells. BMC Med 2008;6:14.

15 Lv XB, Jiao Y, Qing Y, Hu H, Cui X, Lin T, Song E, Yu F: Mir-124 suppresses multiple steps of breast cancer metastasis by targeting a cohort of pro-metastatic genes in vitro. Chin J Cancer 2011;30:821-830.

- 16 Wong KY, So CC, Loong F, Chung LP, Lam WW, Liang R, Li GK, Jin DY, Chim CS: Epigenetic inactivation of the mir-124-1 in haematological malignancies. PLoS One 2011;6:e19027.

17 Xia J, Wu Z, Yu C, He W, Zheng H, He Y, Jian W, Chen L, Zhang L, Li W: Mir-124 inhibits cell proliferation in gastric cancer through down-regulation of sphk1. J Pathol 2012;227:470-480.

18 Griffiths-Jones S, Saini HK, van Dongen S, Enright AJ: Mirbase: Tools for microrna genomics. Nucleic Acids Res 2008;36:D154-158. 


\section{Cellular Physiology and Biochemistry}

Cell Physiol Biochem 2013;31:823-832

\begin{tabular}{l|l}
\hline DOI: $10.1159 / 000350100$ & (c) 2013 S. Karger AG, Basel
\end{tabular}

19 Lee KH, Chen YL, Yeh SD, Hsiao M, Lin JT, Goan YG, Lu PJ: Microrna-330 acts as tumor suppressor and induces apoptosis of prostate cancer cells through e2f1-mediated suppression of akt phosphorylation. Oncogene 2009;28:3360-3370.

20 Han Z, Yang Q Liu B, Wu J, Li Y, Yang C, Jiang Y: Microrna-622 functions as a tumor suppressor by targeting k-ras and enhancing the anticarcinogenic effect of resveratrol. Carcinogenesis 2012;33:131-139.

21 Thomas M, Lange-Grunweller K, Weirauch U, Gutsch D, Aigner A, Grunweller A, Hartmann RK: The protooncogene pim-1 is a target of mir-33a. Oncogene 2012;31:918-928.

-22 Arvanitis DN, Jungas T, Behar A, Davy A: Ephrin-b1 reverse signaling controls a posttranscriptional feedback mechanism via mir-124. Mol Cell Biol 2010;30:2508-2517.

23 Furuta M, Kozaki KI, Tanaka S, Arii S, Imoto I, Inazawa J: Mir-124 and mir-203 are epigenetically silenced tumor-suppressive micrornas in hepatocellular carcinoma. Carcinogenesis 2010;31:766-776.

24 Li KK, Pang JC, Ching AK, Wong CK, Kong X, Wang Y, Zhou L, Chen Z, Ng HK: Mir-124 is frequently downregulated in medulloblastoma and is a negative regulator of slc16a1. Hum Pathol 2009;40:1234-1243.

-25 Wilting SM, van Boerdonk RA, Henken FE, Meijer CJ, Diosdado B, Meijer GA, le Sage C, Agami R, Snijders PJ, Steenbergen RD: Methylation-mediated silencing and tumour suppressive function of hsa-mir-124 in cervical cancer. Mol Cancer 2010;9:167.

26 Zijlstra A, Lewis J, Degryse B, Stuhlmann H, Quigley JP: The inhibition of tumor cell intravasation and subsequent metastasis via regulation of in vivo tumor cell motility by the tetraspanin cd151. Cancer Cell 2008;13:221-234.

-27 Copeland BT, Bowman MJ, Ashman LK: Genetic ablation of the tetraspanin cd151 reduces spontaneous metastatic spread of prostate cancer in the tramp model. Mol Cancer Res 2013;11:95-105.

28 Franco M, Muratori C, Corso S, Tenaglia E, Bertotti A, Capparuccia L, Trusolino L, Comoglio PM, Tamagnone $\mathrm{L}$ : The tetraspanin cd151 is required for met-dependent signaling and tumor cell growth. J Biol Chem 2010;285:38756-38764.

29 Lee JM, Yoo JK, Yoo H, Jung HY, Lee DR, Jeong HC, Oh SH, Chung HM, Kim JK: The novel mir-7515 decreases the proliferation and migration of human lung cancer cells by targeting c-met. Mol Cancer Res 2013;11:4353.

- 30 Klosek SK, Nakashiro K, Hara S, Shintani S, Hasegawa H, Hamakawa H: Cd151 forms a functional complex with c-met in human salivary gland cancer cells. Biochem Biophys Res Commun 2005;336:408-416.

-31 Hashida H, Takabayashi A, Tokuhara T, Hattori N, Taki T, Hasegawa H, Satoh S, Kobayashi N, Yamaoka Y, Miyake M: Clinical significance of transmembrane 4 superfamily in colon cancer. Br J Cancer 2003;89:158167.

- 32 Tokuhara T, Hasegawa H, Hattori N, Ishida H, Taki T, Tachibana S, Sasaki S, Miyake M: Clinical significance of cd151 gene expression in non-small cell lung cancer. Clin Cancer Res 2001;7:4109-4114.

-33 Kohno M, Hasegawa H, Miyake M, Yamamoto T, Fujita S: Cd151 enhances cell motility and metastasis of cancer cells in the presence of focal adhesion kinase. Int J Cancer 2002;97:336-343.

-34 Huang TC, Chang HY, Chen CY, Wu PY, Lee H, Liao YF, Hsu WM, Huang HC, Juan HF: Silencing of mir-124 induces neuroblastoma sk-n-sh cell differentiation, cell cycle arrest and apoptosis through promoting ahr. FEBS Lett 2011;585:3582-3586.

- 35 Hunt S, Jones AV, Hinsley EE, Whawell SA, Lambert DW: Microrna-124 suppresses oral squamous cell carcinoma motility by targeting itgb1. FEBS Lett 2011;585:187-192. 